\title{
CLIMATOLOGIA DO ESTADO DO RIO GRANDE DO NORTE, BRASIL: SISTEMAS ATMOSFÉRICOS ATUANTES E MAPEAMENTO DE TIPOS DE CLIMA
}

\author{
CLIMATOLOGY OF THE STATE OF RIO GRANDE DO NORTE, BRAZIL: \\ ACTIVE ATMOSPHERIC SYSTEMS AND MAPPING OF CLIMATE TYPES \\ CLIMATOLOGÍA DEL ESTADO DE RÍO GRANDE DEL NORTE, BRASIL: \\ SISTEMAS ATMOSFÉRICOS ACTIVOS Y CARTOGRAFÍA DE LOS TIPOS \\ DE CLIMA
}

Marco Túlio Mendonça Diniz - Universidade Federal do Rio Grande do Norte - Rio Grande do Norte - Brasil tuliogeografia@gmail.com

Vítor Hugo Campelo Pereira - Universidade Federal do Rio Grande do Norte - Rio Grande do Norte - Brasil vitor.pereira95@yahoo.com.br

\begin{abstract}
Resumo
0 estado do Rio Grande do Norte não possui um mapeamento de tipos climáticos. 0 mapa de clima do estado, atualmente utilizado pelo governo estadual é apresentado sem a referência metodológica que norteou a delimitação dos tipos de clima do estado, inclusive utilizando nomenclaturas semelhantes para padrões de climas ditos distintos como, por exemplo, os subtipos semiúmidos e subúmidos para os quais não se percebe dessemelhança com base nos nomes. Neste trabalho foram apresentados e analisados os sistemas atmosféricos atuantes no estado e o mapeamento de isoietas e tipos climáticos utilizando informações de 136 postos pluviométricos da SUDENE. A metodologia empregada foi a mesma do IBGE. 0 estado possui dois tipos climáticos - o clima Tropical do Nordeste Oriental, com quatro subtipos climáticos e o Tropical de Zona Equatorial com três subtipos de clima.

Palavras-chave: tipos climáticos, clima do Rio Grande do Norte, climatologia geográfica.
\end{abstract}

\section{Abstract}

The state of Rio Grande do Norte does not have a mapping of climate types. The climate map of the state currently used by the state government lacks a methodological reference that guided the definition of the state's climate types. Also, it uses similar nomenclatures for patterns of different climates. For instance, the semi- and sub-humid subtypes, for which it is not perceived any dissimilarity based on their names. In this work, we presented and analyzed the active atmospheric systems in the state as well as isohyetal and climate types mapping, using information from 136 SUDENE's rain gauges. We employed the methodology used by IBGE. The state has two climatic types: the Tropical East Northeast climate, with four climate subtypes, and the Tropical Equatorial Zone, with three climate subtypes.

Keywords: climate types, climate of the Rio Grande do Norte, geographic climatology.

\section{Resumen}

El estado de Río Grande del Norte no tiene ningún mapeo de tipos de clima. El mapa del clima del estado, actualmente utilizado por el gobierno del estado es presentado sin la referencia metodológica que guió la delimitación de los tipos de clima en el estado, utilizando nomenclaturas semejantes para patrones de climas dichos diferentes como, por ejemplo, los subtipos semi-húmedos y sub-húmedos para los cuales no se percibe 
disimilitud basada en los nombres. En este trabajo se han presentado y analizado los sistemas atmosféricos actuantes en el estado y el mapeo de isoyetas y tipos climáticos utilizando informaciones de 136 puestos pluviómetros de la SUDENE. La metodología fue la misma utilizada por el IBGE. El estado tiene dos tipos de clima - el clima Tropical del Nordeste Oriental, con cuatro subtipos climáticos y el Tropical de Zona Ecuatorial, con tres subtipos climas.

Palabras clave: tipos climáticos, clima del Río Grande del Norte, climatología geográfica.

Introdução

A partir dos anos 1960, autores como Monteiro $(1962,1964)$ passaram a idealizar transformações na Climatologia Geográfica, dentre elas, a necessidade de implementação de um caráter genético à classificação climática (Monteiro, 1962). Assim, esse autor chegou a propor um modelo de classificação para o estado de São Paulo (Monteiro, 1964) que tinha em conta o ritmo climático para tipificação dos climas do estado.

Na década seguinte, EdmonNímer e sua equipe no Instituto Brasileiro de Geografia e Estatística (IBGE) propuseram um modelo metodológico de classificação de climas baseado na "necessidade de conjugar métodos tradicionais a métodos dinâmicos" (Nímer, 1979, p. 75), ou seja, levando em considerações as normais do clima em conjunção com uma classificação genético-dinâmica de climas zonais e regionais.

As propostas de Nímer e Monteiro, apesar das semelhanças em considerar a atuação dos sistemas atmosféricos como elemento fundamental na tipificação dos climas, diferem sob o ponto de vista das normais do clima, que foram consideradas fundamentais pelo primeiro e substituídas pela análise rítmica pelo segundo, que considerava anos padrão e não o período de 30 anos da normal do clima.

Nímer com base em levantamento de material bibliográfico e em análises das normais climatológicas do Brasil (1931-1960) propôs à época uma classificação de climas do Brasil que é oficialmente utilizada pelo IBGE e considerada referência por grande parte dos estudiosos de climatologia geográfica como Mendonça e Danni-Oliveira (2007), só para citar um exemplo, que em seu trabalho utilizam basicamente, a mesma classificação adotada pelo IBGE.

O trabalho do IBGE é referência, sua metodologia é facilmente aplicável e pode ser replicada nas escalas estaduais, contudo o Instituto de Desenvolvimento Sustentável e Meio Ambiente do Rio Grande do Norte (IDEMA), órgão de estudos e planejamento ambiental do estado tem 
utilizado outra referência cartográfica que não encontra paralelo em escala nacional, nem mesmo nos estados vizinhos. O mapa do IDEMA (2013) é apresentado sem a referência metodológica que norteou a delimitação dos tipos de clima do estado, utilizando nomenclaturas semelhantes para padrões de climas ditos distintos, tais como: os subtipos semiúmidos e subúmidos, para os quais não se percebe dessemelhança com base nos nomes. No mapeamento em questão, o município de Caicó e parte do Seridó Potiguar são incluídos no tipo semiúmido, embora estas áreas estejam incluídas nos núcleos desertificação do Brasil (BRASIL, 2005).

A produção sobre a climatologia do Rio Grande do Norte é bastante reduzida, trabalhos de maior repercussão como os de Conti (1995) tem foco no fenômeno da desertificação, e incluem toda a região Nordeste, desse modo, utiliza-se ainda para o estudo e compreensão do clima do Rio Grande do Norte o mapeamento de Nímer (1977), que é o mesmo apresentado atualmente na escala de 1:5.000.000 para o Brasil pelo IBGE (2002). Esse mapa sofreu apenas atualizações na representação da classificação, sem alteração em seus limites, nem tampouco houve atualização dos dados desde a década de 1970.

No momento atual, dispõe-se de dados de uma nova normal climatológica (1961-1990), contudo um mapeamento com base unicamente nessas informações teria resultado semelhante ao já existente (Nímer, 1977), pois são apenas sete as estações do Instituto Nacional de Meteorologia (INMET, 2009) com informações de precipitação pluviométrica para o Rio Grande do Norte, o que inviabiliza um estudo de maior escala. Entretanto, existem informações de postos pluviométricos da Sudene (1990), com dados de136 postos pluviométricos espalhados por todo o estado. Esse trabalho apresenta uma nova proposta de classificação climática do estado do Rio Grande do Norte em escala de 1:500.000 utilizando a mesma metodologia proposta por Nímer (1979), adotada, atualmente, pelo IBGE (2002), a partir de uma disponibilidade muito maior de dados de precipitação (SUDENE, 1990) e com médias de temperatura aferida e estimada para postos pluviométricos espalhados por todo o território do Rio Grande do Norte.

\section{Materiais e métodos}

Neste trabalho utilizou-se como referência metodológica a estrutura do modelo de Nímer (1979), que é constituída por três sistemas fundamentais: 
Primeiro sistema: derivado da climatologia dinâmica é baseado em padrões de circulação atmosférica. Na figura 1 pode ser observada a classificação geral em climas zonais e regionais, nela é possível observar que no Rio Grande do Norte (RN) existem dois tipos climáticos, um Tropical de Zona Equatorial e outro Tropical do Nordeste Oriental. Além do mapa básico (Figura 1), foi produzido por Nímer outro mais complexo, levando em considerações os valores da normal do clima e os sistemas segundo e terceiro.

Segundo sistema: delimitador de regiões térmicas, segundo Nímer (1979) baseado em índices de diferentes autores. No Rio Grande do Norte ocorrem apenas climas quentes, ou seja, com temperaturas superiores aos $18^{\circ} \mathrm{C}$.

Terceiro sistema: delimitador de regiões quanto à umidade, baseado na existência ou não de seca e no comprimento médio da estação seca. A definição de seca é baseada em Bagnouls e Gaussen (1953), os autores consideram mês seco aquele cujo total das precipitações em milímetros é igual ou inferior ao dobro da temperatura média em Graus Celsius ( $\mathrm{P} \leq$ 2T). Nímer (1979) identificou em seu mapeamento que no Rio Grande do Norte ocorrem climas de três meses secos, quatro a cinco meses secos, seis meses secos, sete a oito meses secos e nove a dez meses secos (Figura 1).

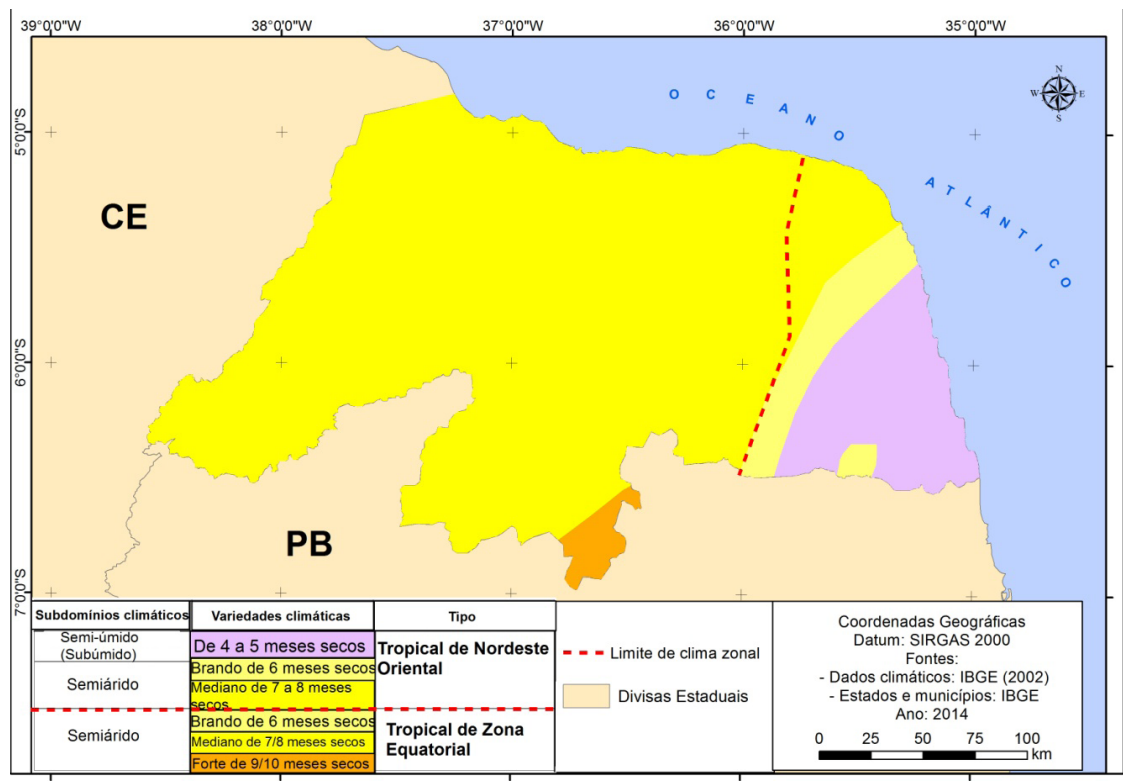

Figura 1 - Mapa de climas do Rio Grande do Norte de Nimer (1979) 
No Quadro 1 pode-se verificar o referencial para a classificação das diferenciações climáticas no domínio dos climas quentes presentes no Rio Grande do Norte.

Quadro 1 - Referencial para classificação das diferenciações climáticas no Rio Grande do Norte

\begin{tabular}{|l|l|l|}
\hline $\begin{array}{l}\text { Subdomínios } \\
\text { Climáticos }\end{array}$ & Variedades Climáticas & Tipo \\
\hline Úmido & De 3 meses secos & \multirow{2}{*}{ Tropical do Nordeste Oriental } \\
\hline Semiúmido (subúmido) & De 4 a 5 meses secos & \\
\hline Semiárido & Brando de 6 meses secos & \\
\cline { 1 - 2 } & Mediano de 7 a 8 meses secos & \\
\hline Semiárido & Brando de 6 meses secos & \multirow{2}{*}{ Tropical de Zona Equatorial } \\
\cline { 1 - 2 } & Mediano de 7 a 8 meses secos & \\
\cline { 2 - 2 } & Forte de 9 a 10 meses secos & \\
\hline
\end{tabular}

Adaptado de Nímer (1977).

Neste trabalho, ao invés de usar apenas os dados de precipitação das sete estações disponíveis nas Normais Climatológicas do Brasil, assim como no trabalho de Conti (1995), foram utilizados os dados mensais de precipitação pluviométrica da série histórica da Superintendência do Desenvolvimento do Nordeste - Sudene (1990) que tiveram suas médias mensais e anuais calculadas pelo Departamento de Ciências Atmosféricas - DCA da Universidade Federal de Campina Grande - UFCG (DCA/UFCG, on-line) disponibilizados na internet. A temperatura média foi estimada pelo mesmo DCA/UFCG (on-line).

Para tabulação dos dados e confecção dos gráficos foi utilizado o software Microsoft Excel 2010, a partir deles, foram feitos os cálculos para determinação da quantidade média de meses secos por ano nos postos pluviométricos da Sudene espalhados por todo o estado do Rio Grande do Norte (Figura 2). Os climogramas elaborados são denominados “Ombrotérmicos”, pois apresentam temperatura e precipitação com médias mensais, destacando os meses chuvosos quando as barras ultrapassam a linha das temperaturas.

Os mapeamentos relativos ao clima do Rio Grande do Norte foram produzidos com base nos dados da Sudene (1990), que por sua vez foram 
georreferenciados e analisados em plataforma de Sistema de Informação Geográfica (SIG), no software ArcGIS 10.2.2.

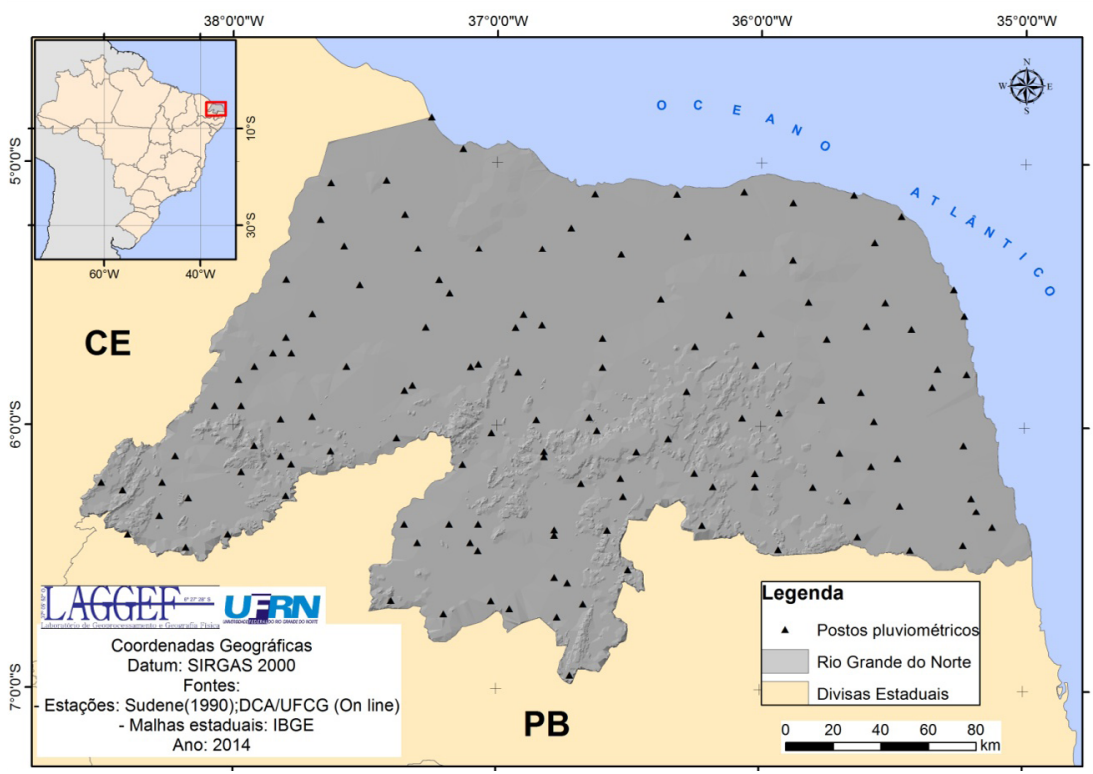

Figura 2 - Localização dos postos pluviométricos analisados.

Fonte: Sudene, 1990.

As informações sobre precipitação e quantificação de meses secos foram interpoladas visando à modelagem de sua variação espacial, através da técnica de krigagem ordinária ${ }^{1}$. Dessa maneira, foi possível gerar representações cartográficas relativas às isoietas e distribuição dos meses secos, subsidiando assim o mapeamento e análise dos tipos climáticos na área estudada.

Climatologia do Rio Grande do Norte: sistemas atmosféricos atuantes, fatores geográficos e distribuição da precipitação

Conforme Molion e Bernardo (2002), os mecanismos dinâmicos que produzem chuvas no Nordeste do Brasil (NEB) podem ser classificados em mecanismos de grande escala, mesoescala e microescala, sendo os 
primeiros responsáveis pela maior parte da precipitação observada no Rio Grande do Norte (RN).

No RN, o único sistema de grande escala responsável por precipitações pluviométricas é a Zona de Convergência Intertropical (ZCIT), uma vez que frentes frias não ocorrem em território potiguar.

Todo o estado está sob influência da ZCIT, considerado o sistema gerador mais importante de precipitação sobre a região equatorial dos oceanos Atlântico, Pacífico e Índico e nas áreas continentais adjacentes (Melo et al., 2009) como no caso do RN. O sistema compõe o que Nímer (1977) denominou de correntes perturbadas de Norte.

De acordo com Melo et al. (2009, p. 26):

Um conjunto de variáveis meteorológicas que atua sobre a faixa equatorial dos oceanos pode definir a ZCIT, a saber: a Zona de Convergência dos Alísios (ZCA), a região do cavado equatorial, as áreas de máxima Temperatura da Superfície do Mar (TSM) e de máxima convergência de massa, e a banda de máxima cobertura de nuvens convectivas.

A confluência dos alísios de Nordeste e de Sudeste e a convergência de massas em baixos níveis favorecem o transporte de umidade e o aumento da atividade convectiva, em especial sobre o NEB. Pode-se dizer que na ZCIT ocorre a confluência das Massas Equatoriais do Atlântico Norte e Sul, adentrando no Rio Grande do Norte uma massa de ar unificada denominada Massa Equatorial Atlântica (mEa), por causa da predominância desse sistema equatorial de duas estações, uma chuvosa e outra seca, saiu a denominação do Clima Tropical de Zona Equatorial, que ocorre no meio-oeste do estado.

Segundo os estudos de Melo et al. (2009) em relação ao Atlântico Equatorial, a ZCIT migra sazonalmente de sua posição mais ao norte $\left(14^{\circ} \mathrm{N}\right.$, agosto-setembro), para sua posição mais ao sul ( $2^{\circ} \mathrm{S}$, março-abril). Os autores afirmam ainda que "em anos chuvosos, a ZCIT pode atingir até $5^{\circ} \mathrm{S}$, perto da costa nordestina”. Essas posições tratam do centro de atuação do sistema, em sua banda principal, podendo ocorrer uma banda secundária no Hemisfério Sul (HS) que chegam a atingir o estado de Sergipe.

A atuação da ZCIT no RN é responsável pela maior parte da precipitação registrada no primeiro semestre do ano. Na área do Clima Tropical de Zona Equatorial a ZCIT é responsável pela maior parte das chuvas registradas, sendo nessas áreas, o quadrimestre mais chuvoso de fevereiro a maio, 
já na área do Clima Tropical do Nordeste Oriental, junto à ZCIT, sistemas de mesoescala também tem papel relevante nos totais pluviométricos anuais.

$\mathrm{O}$ fator maritimidade tem forte efeito sob o clima do RN nos totais pluviométricos, mesmo nos meses de atuação da ZCIT. Basta comparar os totais pluviométricos registrados em Natal (1562,7 mm/ano em média) no litoral oriental e São Paulo do Potengi (557,2 mm/ano em média) afastada apenas $64 \mathrm{~km}$ de Natal em linha reta. Entre março e maio precipita em média mais $690 \mathrm{~mm}$ em Natal (mais que o total anual de São Paulo do Potengi) enquanto que no segundo, a média nesses mesmos três meses não chega a $390 \mathrm{~mm} / \mathrm{ano}$.

Um sistema atmosférico de mesoescala é o segundo em importância nos totais de precipitação pluviométrica no RN, são as Perturbações Ondulatórias no Campo dos Alísios (POA), que ocorrem graças à penetração profunda de sistemas frontais do Hemisfério Norte (HN), em latitudes equatoriais. As POA se propagam para oeste, cruzam o Equador, mas não se desenvolvem sobre o oceano. Porém, geralmente, intensificam-se quando chegam à costa devido ao aumento de convergência de umidade e ao contraste térmico continente-oceano (Molion e Bernardo, 2002). Em caso de associação entre POA e brisa marítima, chegam a penetrar $300 \mathrm{~km}$ para o interior do continente, levando chuvas até a Borborema Potiguar, ou mesmo nos outros planaltos interiores (associada ao efeito orográfico). Já em caso de confluírem com a brisa terrestre, podem provocar tempestades com precipitações superiores aos $50 \mathrm{~mm} / \mathrm{dia}$, o que ocorre, geralmente, nas madrugadas e início da manhã, sendo comum ocorrer no litoral oriental do estado.

As POA são fenômenos que ocorrem entre março e maio, quando originárias da África e entre junho e agosto quando provenientes do Atlântico Sul. São também chamadas de Distúrbios Ondulatórios de Leste (Machado et al., 2009) ou apenas "ondas de leste", e como seu nome sugere, são provenientes do oriente, atingindo prioritariamente o litoral oriental do NEB, já que esse tem sua conformação frontal à rota do fenômeno. Dessa forma, o litoral setentrional do RN raramente tem chuvas associadas a este fenômeno, e quando ocorrem precipitações, estas são bem inferiores às do litoral oriental, pois as POA chegam primeiro a este, perdem umidade e só depois atingem o litoral setentrional.

Outro sistema de mesoescala atuante são os complexos convectivos, que produzem chuvas isoladas (FUNCEME, s.d) e que se formam devido às condições locais favoráveis (temperatura, relevo, pressão etc.). Esse 
fenômeno não responde por aumento de precipitação em nenhuma área específica do estado.

Vórtices Ciclônicos de Altos Níveis (VCAN), também atingem o RN, mas podem produzir chuva em qualquer parte do estado, conforme sua posição, que é variável. Esses fenômenos se formam no Atlântico, mas avançam por todo interior do Nordeste produzindo nuvens de chuva em sua periferia e subsidindo ar seco em seu centro, formando localmente e de forma temporária, áreas de altas pressões.

Um sistema de mesoescala que tem considerável importância na elevação dos totais pluviométricos no litoral oriental e grande importância na inibição de chuvas no litoral setentrional do estado são as brisas marinhas e terrestres. Este último aspecto até pouco tempo não era citado na literatura acerca do clima do RN, contudo Diniz (2013), ao estudar os condicionantes para a produção de sal marinho no estado, percebeu que as brisas terrestres eram extremamente importantes na climatologia do litoral setentrional do RN.

Sobre as brisas e o sistema de circulação atmosférica Teixeira (2008) comenta que:

O fenômeno de circulação da brisa tipifica um sistema atmosférico de mesoescala (Rotunno et al., 1992), e de regiões costeiras (Ahrens, 2000). Identificadas pelos antigos gregos desde cerca de 350 a.C. e representando um sistema de vento local (Vianello e Alves, 1991), ou um regime específico de vento, de escala diurna, decorrente das diferenças térmicas entre as superfícies terrestres e marítimas que levam a diferenças de pressão do ar em baixos níveis, sobre essas superfícies, as brisas são de dois tipos: de mar e de terra (Teixeira, 2008, p. 283).

Usualmente é atribuída maior relevância ao fenômeno da brisa marítima, pois esta costuma carregar umidade do oceano para o interior do continente até distâncias de cerca de $300 \mathrm{~km}$. Ao contrário, a brisa terrestre costuma provocar precipitações sobre o oceano. Entretanto, em estudo clássico Kousky (1980) percebeu que áreas costeiras do NEB (especialmente no trecho oriental) experimentam o máximo de precipitação no período noturno (entre $21 \mathrm{~h}$ e $9 \mathrm{~h}$ no horário local). Isso ocorreria "devido à convergência entre o fluxo médio de ar próximo à superfície procedente do oceano, e o fluxo superficial do continente para o mar devido à brisa terrestre" (Teixeira, 2008, p. 283). Nas áreas entre $150-300 \mathrm{~km}$ para o interior, o máximo de precipitação seria registrado entre $15 \mathrm{~h}$ e $21 \mathrm{~h}$ local. 
Da análise da obra de Kousky (1980) é possível perceber que o litoral setentrional do RN se encontra abrigado pelos ventos alísios de leste e sudeste, que em confluência com a brisa terrestre de oeste seriam responsáveis por precipitação noturna no litoral oriental do estado.

No litoral setentrional a brisa terrestre provém de sul, sudeste ou sudoeste, o que é responsável por afastar nuvens de chuva da costa, provocando precipitação pluviométrica sobre o Atlântico. O Fenômeno pode ser visualizado em imagens de satélite com considerável frequência. Na Figura 3, é possível visualizar o evento aqui analisado, sendo possível ainda perceber a formação de dois arcos de nuvens sobre o oceano a norte dos dois trechos côncavos do litoral setentrional do Nordeste, principalmente, sobre o litoral setentrional potiguar, assim como é possível visualizar considerável nebulosidade no mesmo horário (início da manhã) na porção mais oriental do estado do RN.

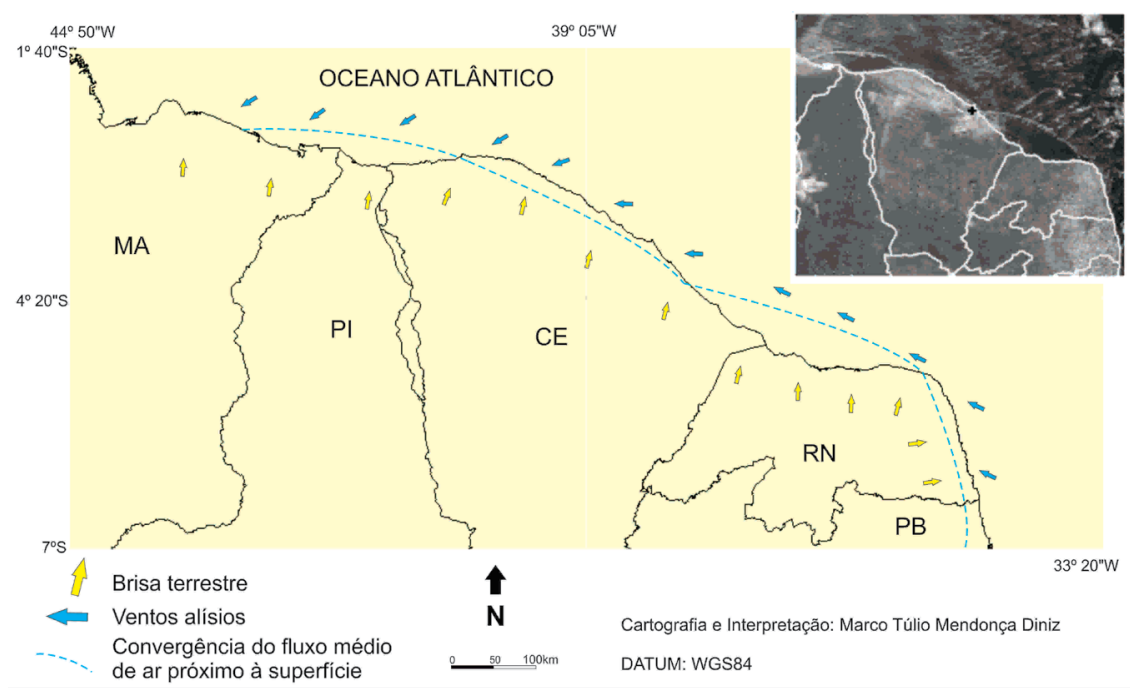

Figura 3 - Fluxo médio do ar próximo à superfície no Litoral do Nordeste em face de brisa terrestre (à noite). No canto superior direito, pode ser visualizada imagem NOAA-14, 19/01/2007, 8h35min local, mostrando linhas de nuvens associadas a brisas terrestres.

Fortaleza é marcada como uma pequena cruz 
A concavidade de trechos do litoral setentrional no NEB faz com que a convergência em baixos níveis da brisa terrestre com os ventos sinóticos (Alísios de sudeste) origine uma frente de brisa "no oceano, que dá origem em geral, a nuvens dispostas na forma de um grande arco com concavidade contrária à concavidade da costa” (Teixeira, 2008, p. 287; Figura 3).

A brisa terrestre é, portanto, um fator que concorre para o aumento das precipitações no litoral oriental. De modo contrário, as regiões produtoras de sal marinho do litoral setentrional, são extremamente desfavorecidas do ponto de vista de precipitação pelo fenômeno da brisa terrestre, que tende a afastar os ventos sinóticos da costa, gerando convergência de nuvens de chuva sobre o oceano, o que diminui seus totais pluviométricos, assim como a frequência de chuvas. Essa diminuição na precipitação é identificada quando da ocorrência de tempo chuvoso no estado, tanto por ocasião de atuação da ZCIT, como em razão da atuação das POA.

Pode-se afirmar que a maritimidade é um elemento que concorre para diminuição dos totais pluviométricos no litoral setentrional do RN, já que cidades mais interioranas como Baraúnas na Chapada do Apodi (cerca de $100 \mathrm{~km}$ afastados do oceano), têm taxa de precipitação média de 845,4 $\mathrm{mm} / \mathrm{ano}$, bem superior às que são registradas em Macau (537 mm/ano) ou Mossoró (672,5mm/ano), maiores produtores de sal marinho do Brasil.

Dentre os mecanismos de microescala, as circulações orográficas também têm papel de destaque na distribuição da precipitação média anual no RN. Esses mecanismos são diretamente controlados por dois fatores geográficos do clima, o relevo (e sua posição em relação aos ventos predominantes) e a altitude.

Os principais planaltos do Rio Grande do Norte, apesar de sua modesta altitude, têm papel decisivo no aumento ou diminuição nos totais pluviométricos do estado, conforme o posto pluviométrico esteja localizado à barlavento ou à sotavento desse planalto.

Na figura 4 podem ser identificadas as principais formas planálticas, a maior delas o planalto da Borborema que se estende além do RN pelos estados da Paraíba, Pernambuco e Alagoas. Particularmente, esta feição e alguns maciços a ela associadas no estado Paraibano tem contribuição significativa para a compreensão da distribuição dos totais pluviométricos mensais registrados no interior do Rio Grande do Norte.

Na figura 4 tem-se um quadro com informações selecionadas da precipitação média e altitude de postos pluviométricos que estão localizados 
em uma direção aproximadamente SE-NW, uns em relação aos outros, aproximadamente a mesma direção na qual se movimentam os ventos sinóticos na área segundo as normais climatológicas das estações de Natal/ RN, Cruzeta/RN, Campina Grande/PB, João Pessoa/PB.
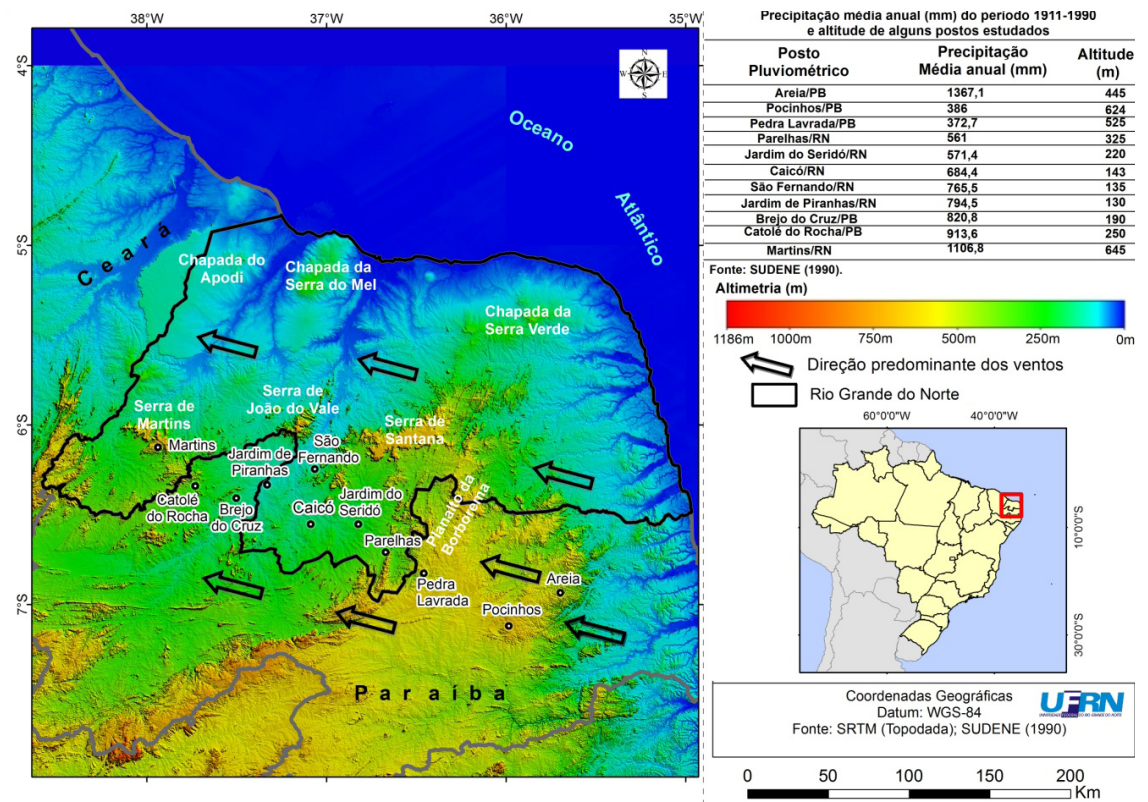

Figura 4 - Relevo do Rio Grande do Norte e estados vizinhos

Fonte da imagem: SRTM (Topodata).

Ao analisar os dados é possível constatar que a altitude compreendida isoladamente não é fator determinante para as médias de precipitação pluviométricas em alguns postos selecionados nesta área ao norte do Planalto da Borborema. Em Martins/RN, a orografia tem papel preponderante nas taxas médias de precipitação, chegando 1106,8 mm/ano, quase três vezes mais que em Pocinhos/PB, onde o posto pluviométrico está localizado em altitude semelhante $(624 \mathrm{~m})$ à de Martins (645 m). A explicação reside no fato de Pocinhos estar posicionada exatamente a sotavento da escarpa oriental da Borborema; já Martins está posicionada por sobre um platô e voltada para a escarpa de barlavento da Serra do Martins. 
O posto pluviométrico de Areia/PB tem altitude inferior $(445 \mathrm{~m})$ à de Pocinhos, mas está posicionado em um maciço a barlavento da Borborema, voltada para o litoral oriental do Nordeste, o que é responsável por um sensível aumento de sua precipitação média, que é de 1367,1 mm/ano.

Em especial, a Região Seridó do Rio Grande do Norte tem suas médias pluviométricas e duração da estação chuvosa influenciadas pelo efeito do relevo. Parelhas (no sopé da encosta ocidental da Borborema Potiguar) registra apenas $561 \mathrm{~mm} / \mathrm{ano}$ em média, assim, quanto mais afastado está o posto pluviométrico da encosta de sotavento da Borborema, maiores tendem a ser as médias de precipitação anual, como os 571,4 mm/ ano em Jardim do Seridó, 684,8 mm/ano em Caicó, 765,5 mm/ano em São Fernando e 794,5 em Jardim de Piranhas. A média cresce mais ainda na região de Catolé do Rocha/PB, até o máximo registrado no interior do $\mathrm{RN}$, 1106,8 mm/ano em Martins no platô do planalto.

Na figura 5 é possível visualizar que as médias pluviométricas do estado tendem a ser mais elevadas na parte oriental, por influência da maritimidade e de sua posição frontal à rota de migração dos sistemas causadores de chuvas que provêm de leste como a ZCIT e as POA. Os persistentes alísios de sudeste são responsáveis pelas incursões constantes da Massa Tropical Atlântica (mTa) e da Massa Equatorial do Atlântico (mEa) nessa área. A porção mais a sudoeste do estado tem seus totais médios elevados pela presença de maiores altitudes como nas serras de Martins (1106,8 mm/ano) e Luiz Gomes (929,6 mm/ano).

O litoral setentrional do estado é o trecho mais seco de toda a costa brasileira, com média pluviométrica de 537,6 mm/ano em Macau. Os totais médios tendem a crescer à medida que se afasta da porção côncava central das proximidades de Macau, que tem suas médias pluviométricas diminuídas pelos fenômenos de brisa terrestre e marinha. Esse fato pode ser identificado a leste como em Touros com 1037,1 mm/ano e um pouco menos para oeste como em Tibau com 892,1 mm/ano.

Este trecho mais seco que ocorre no litoral setentrional se prolonga para região central do estado, numa área a sotavento da Borborema e da Serra de Santana, onde são registrados 400,8 mm/ano no Sítio Recanto em Cerro Corá, localizada na porção centro-leste do estado, a mais seca, envolvida pela isoieta de $500 \mathrm{~mm}$.

O Seridó Oriental (porção centro-sul do estado) é envolvido pela isoieta de $600 \mathrm{~mm}$, localizado no sopé da escarpa oriental da Borborema 
como em Parelhas (561 mm/ano). A aridez é maior na própria escarpa oriental e em baixos patamares da Borborema Potiguar, que se encontram a sotavento da escarpa oriental (úmida e subúmida), esta área é envolvida pela isolinha de $500 \mathrm{~mm}$, registrando apenas $457,3 \mathrm{~mm}$ /ano em Currais Novos (350 m de altitude) e $459 \mathrm{~mm} / \mathrm{ano}$ em Equador (500 m de altitude), sendo esta uma das áreas mais áridas do estado, junto aos sertões centrais do RN.

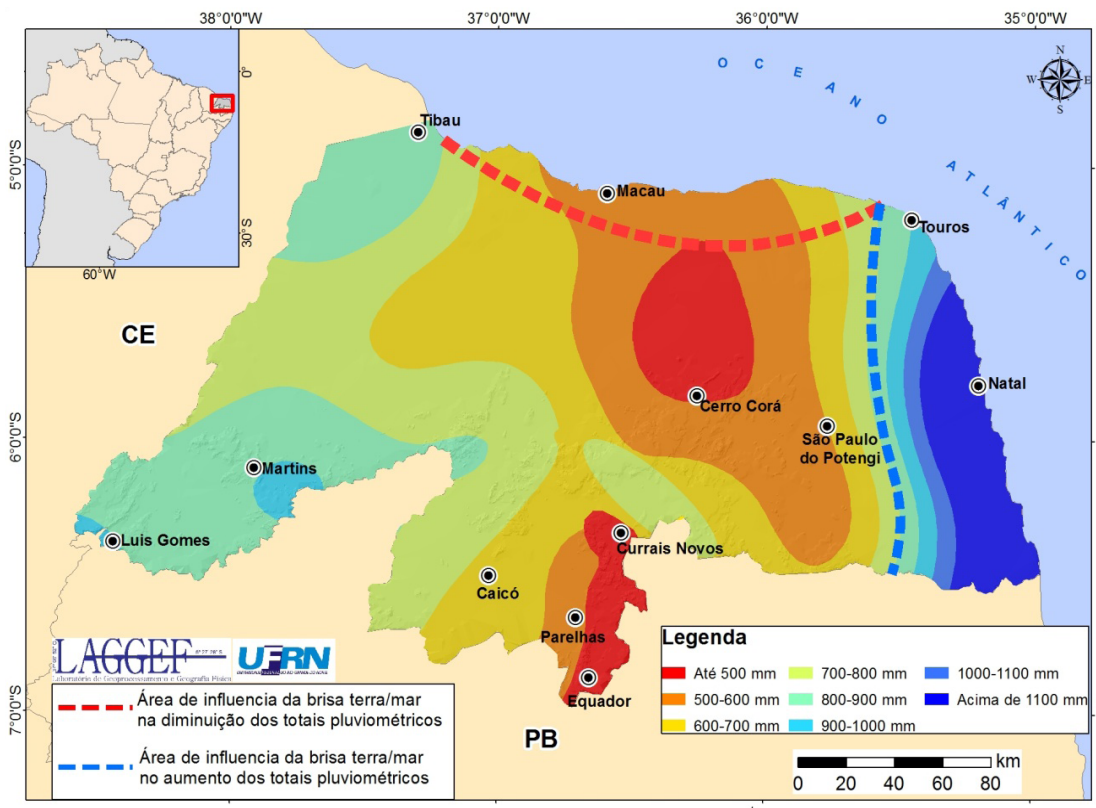

Figura 5 - Mapa de Isoietas do Rio Grande do Norte

Fonte: Sudene (1990). Interpretação e elaboração dos autores.

\section{Tipos Climáticos do Rio Grande do Norte}

Na figura 6 os dois tipos climáticos do Rio Grande do Norte podem ser visualizados, ou seja, um Tropical do Nordeste Oriental e outro Tropical de Zona Equatorial.

Na Figura 7 são apresentados climogramas ombrotérmicos, os três primeiros representam bem o clima Tropical do Nordeste Oriental. O 
de Natal retrata a realidade de seu subdomínio úmido. Em Natal têm-se apenas três meses secos, nesta área a estação chuvosa se prolonga desde janeiro até setembro, sendo o trimestre mais chuvoso de abril a junho, com chuvas predominantes de outono-inverno.

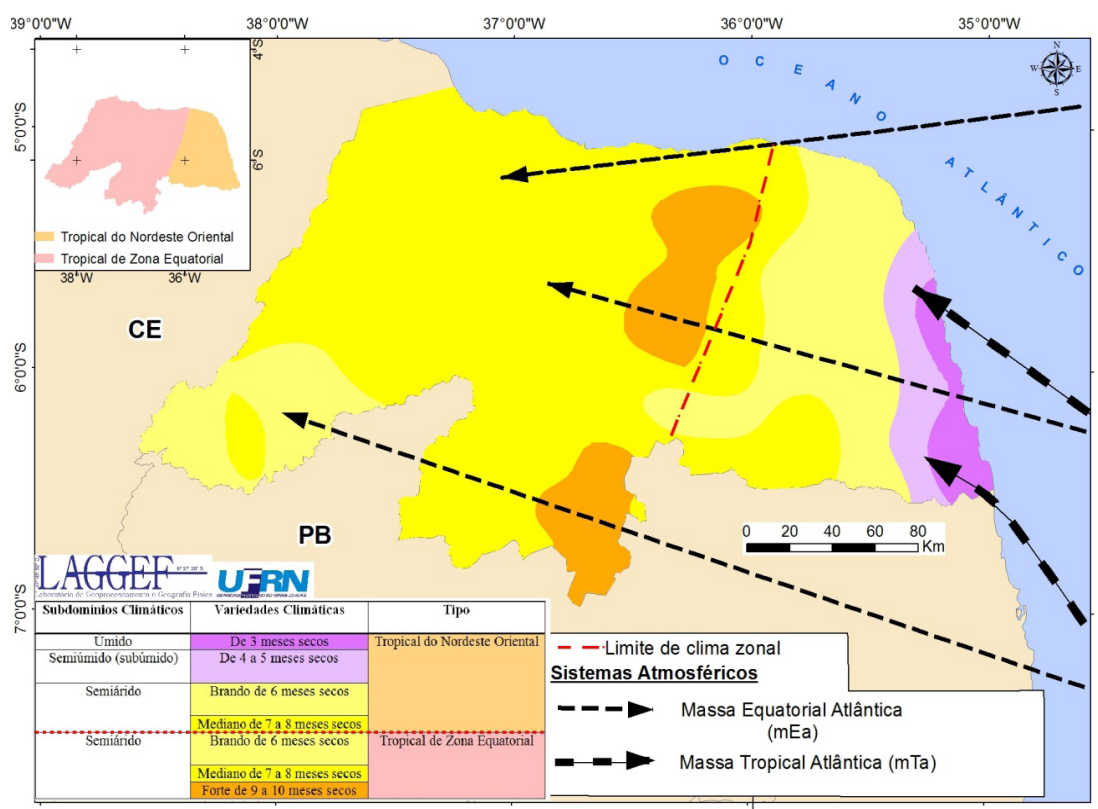

Figura 6 - Mapa de climas do Rio Grande do Norte

Fonte: Sudene (1990). Interpretação dos autores.

Touros representa o subdomínio subúmido (Tipo Tropical do Nordeste Oriental), com cinco meses secos, com trimestre mais chuvoso de abril a junho. A estação chuvosa se prolonga de março a julho (chuvas de outono-inverno).

O climograma de São Paulo do Potengi comprova que no clima Tropical do Nordeste Oriental existem subtipos semiáridos. A área tem seis meses secos, com estação chuvosa indo de fevereiro a julho (sendo que fevereiro tem apenas 53,3 mm em média), ou seja, também com chuvas de outono-inverno. Contudo, esta é uma área de transição, já que o trimestre mais chuvoso é de março a maio. 
Natal (RN) - Clima Quente e Úmido do tipo Tropical do Nordeste Oriental com 3 meses secos

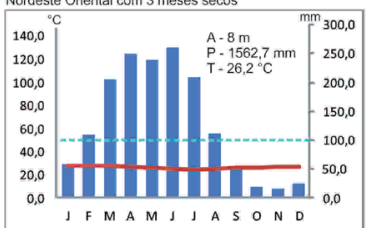

Currais Novos (RN) - Clima Quente e Semiárido do tipo Tropical de Zona Equatorial com 8 meses secos

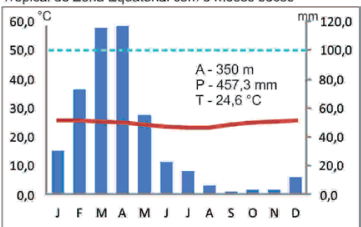

Caicó (RN) - Clima Quente e Semiarido do tipo Tropical de Zona Equatorial com 7 meses secos

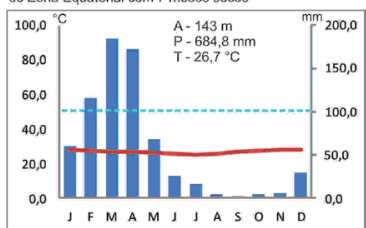

Touros (RN) - Clima Quente e Subúmido do tipo Tropical do Nordeste Oriental com 5 meses secos

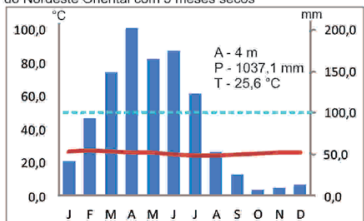

Sítio Recanto, Cerro Corá (RN) - Clima Quente e Semiárid do tipo Tropical de Zona Equatorial com 9 meses secos

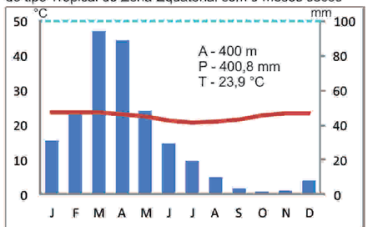

Martins (RN) - Clima Quente e Semiárido do tipo Tropical de Zona Equatorial com 6 meses secos

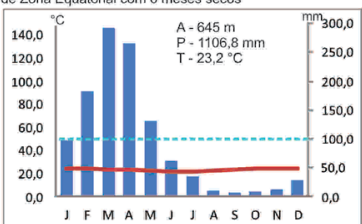

Săo Paulo do Potengi (RN) - Clima Quente e Semiárico do tipo Tropical do Nordeste Oriental com 7 meses secos tipo Tropical do Nordeste Oriental com 7 meses secos

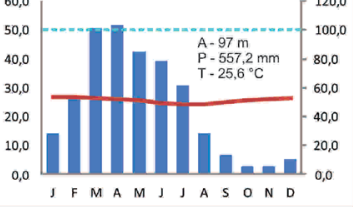

Macau (RN) - Clima Ouente e Semiśrido

do tipo Tropical de Zona Equatorial com 8 meses secos

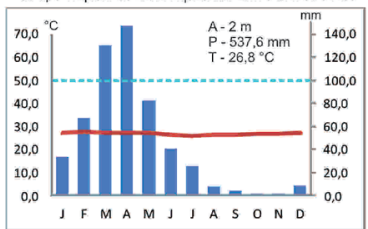

Luiz Gomes (RN) - Clima Quente e Semiárido do tipo Tropical de Zona Equatorial com 6 meses secos

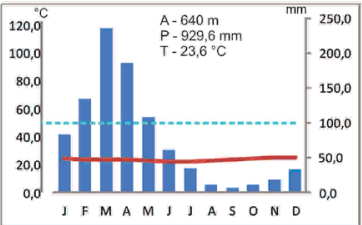

-n- - Altura de $100 \mathrm{~mm}$ de precipitação — Precipitação em milímetros $(\mathrm{mm})$ — Temperatura em Graus Celsius $\left({ }^{\circ} \mathrm{C}\right)$ $\mathrm{A}=$ Altitude do posto pluviométrico em $\mathrm{m} ; \mathrm{P}=$ Precipitação média anual em $\mathrm{mm} ; \mathrm{T}=$ Temperatura média anual em ${ }^{\circ} \mathrm{C}$

Figura 7 - Climogramas Ombrotérmicos de Natal, Touros, São Paulo do Potengi, Currais Novos, Sítio Recanto (Cerro Corá), Macau, Caicó, Martins e Luiz Gomes. A linha vermelha representa temperatura média, as barras em azul escuro representam a precipitação média. Mês com precipitação abaixo da linha de temperatura representa mês seco. A linha pontilhada em azul claro representa a altura de precipitação de $100 \mathrm{~mm}$.

Fonte: Sudene (1990).

Os seis climogramas seguintes representam o tipo Tropical de Zona Equatorial. Currais Novos exemplifica uma área da Borborema de clima semiárido com oito meses secos e curta estação chuvosa de fevereiro a maio, com trimestre mais chuvoso de fevereiro a abril, ou seja, com chuvas de verão-outono. Essa é a principal característica desse tipo climático que ocupa grande área do Nordeste Setentrional e a maior parte do RN.

O Sítio Recanto é a área mais árida do estado, com apenas 400,8 $\mathrm{mm} / \mathrm{ano}$ em média e com estação chuvosa de apenas três meses, de março a maio (chuvas de verão-outono) sendo os outros nove meses secos.

Macau é a cidade litorânea mais seca do Brasil, com oito meses secos, estação chuvosa de verão-outono, indo de fevereiro a maio, precipitação 
média anual de apenas 537,6 mm. A aridez dessa área se deve em maior parte aos fenômenos de brisa de terra-mar já explicados. Caicó, no Sertão do Seridó tem clima semiárido com sete meses secos, sendo o trimestre mais chuvoso de fevereiro a abril (chuvas de verão-outono).

Os climogramas de Martins e Luiz Gomes retratam bem a influência do relevo nesse tipo climático, pois torna mais branda a semiaridez. Essas duas áreas elevadas (645 m e 640 m respectivamente) têm seis meses chuvosos e outros seis meses secos. Com chuvas de janeiro a junho, o que mostra que alguns sistemas de leste (mais fortes no inverno) chegam a atingir áreas interioranas, mas com trimestre mais chuvoso de fevereiro a abril (verão-outono), o que marca a maior influência da ZCIT nos totais anuais.

\section{Considerações finais}

Comparando os mapeamentos e classificações climáticas relativas ao estado do Rio Grande do Norte com os resultados obtidos por esse estudo, foram verificadas algumas diferenças, que se justificam pela metodologia adotada e/ou pelos dados utilizados como referenciais, bem como pela escala de análise.

A produção desse estudo se deu a partir da utilização de uma maior quantidade de dados climáticos e uma escala de trabalho mais detalhada do que estudos anteriores correlatos ao tema para o mesmo recorte espacial, basta comparar as Figuras 6 e 1 para que se possa perceber o maior detalhamento ora apresentado.

Assim, aqui se apresentam dados mais precisos sobre a climatologia do estado do Rio Grande do Norte e que podem subsidiar uma ampla gama de estudos em áreas diversas, tais como: análises geoambientais, estudos sobre desertificação e seca, manejo de solo, recursos hídricos, geomorfologia, dentre outros.

Espera-se com este trabalho que possam ser fomentadas pesquisas, considerando a climatologia do Rio Grande do Norte dentro de um sistema de referência nacional.

Espera-se também que este trabalho, assim como a primeira experiência de mapeamento de tipos climáticos realizado por Diniz et al. (2014) para o estado do Sergipe, sirva de estímulo para mapeamentos atualizados em todos os estados nordestinos, utilizando os dados de precipitação 
pluviométrica disponibilizados pela Sudene e um sistema metodológico que possa ter a mesma referência em todos os estados do Nordeste e em outras regiões do país.

Nota

${ }^{1}$ De acordo com Camargo et al. (2004), a krigagem "compreende um conjunto de técnicas de estimação e predição de superfícies baseada na modelagem da estrutura de correlação espacial".

\section{Referências}

BAGNOULS, F.; GAUSSEN, H. Saison sècheet indice xérothermique. Bulletin de la Société d'histoire naturelle de Toulouse, Toulouse, n. 88, v.1, 1953. p. 193 - 240. BRASIL. Ministério do Meio Ambiente. Panorama da Desertificação do Rio Grande do Norte. Natal: MMA/SERHID, 2005.

CAMARGO, E. C. G.; FUCKS, S. D.; CÂMARA, G. Análise espacial de superfícies. Brasília: Embrapa, 2004.

CONTI, J. B. Desertificação em áreas tropicais - Proposta de Metodologia de estudo Aplicado ao Nordeste Brasileiro. 1995. Tese (Livre Docência) - Universidade de São Paulo, São Paulo, 1995.

DCA/UFCG. Departamento de Ciências Atmosféricas (DCA) - Universidade Federal de Campina Grande (UFCG). Clima. Campina Grande, s.d.. Disponível em: <http://www.dca.ufcg.edu.br/clima/>. Acesso em: 10 ago. 2012.

DINIZ, M. T. M. Condicionantes socioeconômicos e naturais para a produção de sal marinho no Brasil: as particularidades da principal região produtora. 2013. 227 p. Tese (Doutorado em Geografia) - Universidade Estadual do Ceará, Centro de Ciências da Saúde, Fortaleza. 2013.

DINIZ, M. T. M.; MEDEIROS, S. C.; CUNHA, C. J. Sistemas atmosféricos atuantes e diversidade pluviométrica em Sergipe. Boletim Goiano de Geografia (Online), v. 34, n. 1, 2014. p. 17-34.

FUNCEME. Sistemas atmosféricos atuantes sobre o Nordeste. s.d. Disponível em: $<$ http://www.funceme.br/index.php/areas/tempo/saiba-mais/sistemas-atmos fericos-atuantes-sobre-o-nordeste>. Acesso em: 19 set. 2014.

IBGE. Diretoria de Geociências - DGC/ Coordenação de Recursos Naturais e Estudos Ambientais- CREN. Mapa de Clima do Brasil. Rio de Janeiro, IBGE, 2002. Mapa colorido.

IDEMA. Anuário Estatístico do Rio Grande do Norte - 2012. Natal, IDEMA, 2013. 
INMET. Normais Climatológicas do Brasil 1961-1990. RAMOS, A. M.; RODRIGUES, A. L.; SANTOS, A. R.; FORTES, L. T. G. (Org.). Brasília: INMET, 2009.

KOUSKY, V. E. Diurnall rainfall variation in the Northeast Brazil. Monthly Weather Review, Boston, v.108, n. 4, 1980. p. 488-498.

MACHADO, L. A. T.; FERREIRA, N. J.; LAURENT, H.; DIEDHIOU, A. Distúrbios ondulatórios de leste. In: Cavalcanti, I. F. A. et al. (Org.). Tempo e Clima no Brasil. São Paulo: Oficina de Texto, 2009. p. 61-74.

MELO, A. B. C.; CAVALCANTI, I. F de A.; SOUZA, P. P. Zona de Convergência Intertropical do Atlântico. In: CAVALCANTI, I. F. A.; FERREIRA, N. J.; SILVA, M. G. A. J.; DIAS, M. A. F. S. (Org.). Tempo e Clima no Brasil. São Paulo: Oficina de Textos, 2009. p. 26-42.

MENDONÇA, F.; DANNI-OLIVEIRA, I. M. Climatologia: noções básicas e climas do Brasil. São Paulo: Oficina de Textos, 2007.

MOLION, L. C. B.; BERNARDO, S. O. Uma revisão da dinâmica das chuvas no nordeste brasileiro. Revista Brasileira de Meteorologia, Rio de Janeiro, v. 17, n. 1, 2002. p. 1-10.

MONTEIRO, C. A. F. Da necessidade de um caráter genético a classificação climática. Revista Geográfica, v. 31, n. 57, 1962. p. 29-44.

; C. A. F. Sobre um índice de participação das massas de ar e sua aplicabilidade à classificação climática. Revista Geográfica, v. 33, n. 61, 1964. p. 55-69.

NÍMER, E. Clima. In: BRASIL. Instituto Brasileiro de Geografia e Estatística. Geografia do Brasil: Região Nordeste. Rio de Janeiro: IBGE, 1977.

; E. Um Modelo Metodológico da Classificação de Climas. Revista Brasileira de Geografia, v. 41 n. 4, 1979. p. 59-89.

SUDENE. Dados pluviométricos mensais do Nordeste. Recife, 1990. (Série Pluviometria 1 a 10).

TEIXEIRA, R. F. B. O fenômeno da brisa e sua relação com a chuva sobre Fortaleza-CE. Revista Brasileira de Meteorologia, v.23, n.3, 2008. p. 282-291.

Marco Túlio Mendonça Diniz - Possui Graduação, Mestrado e Doutorado em Geografia pela Universidade Estadual do Ceará. Atualmente é professor da Universidade Federal do Rio Grande do Norte.

Vítor Hugo Campelo Pereira - Possui Graduação e Mestrado em Geografia pela Universidade Federal do Rio Grande do Norte. Atualmente é Doutorando em Geografia pela Universidade Federal do Rio Grande do Norte. 